\title{
INVESTIGATION OF POSSIBLE ORGANIZATIONAL CHANGES TO THE HEALTH INSURANCE SYSTEM IN VIETNAM
}

\author{
Mai Thi DOAN (D) ${ }^{*}$, Sergey I. DUKHNO (D)2 \\ ${ }^{1}$ Faculty of Economics, Saint Petersburg State University, Universitetskaya nab., \\ 7/9, 199034, Saint Petersburg, Russian Federation \\ ${ }^{2}$ Individual entrepreneur, Skalistaya 3, 186202 Western Konchezero, Kondopozhsky District, \\ Republic of Karelia, Russian Federation
}

Received 28 February 2021; accepted 1 April 2021

\begin{abstract}
Purpose - to identify the prerequisites for organizational changes of the emerging health insurance system in Vietnam.

Research methodology - comparative analysis, statistical analysis, case study.

Findings - the obligatory health insurance in Vietnam performs its functions only partially. There is still high level of out-of-pocket spending on medical services. First we identified one of the most important challenges to the health insurance system in Vietnam, namely, the population aging. Secondly, we identified and analyzed and the prerequisites (the pre-existing conditions), which can become the basis for the reorganization of the existing health insurance system without major reforms: (1) the cultural values of Asian society, which allow to build a community-based type model of living for the elderly on the basis of "equal with equal"; (2) technological advances in medicine that extend the healthy life of the elderly, (3) trust in traditional medicine, which allows widen the coverage of the poorest "elderly households".

Practical implications - the results of the study require attention from the government and insurance providers when rethinking of organizing process for mandatory medical insurance.

Originality/Value - we have identified the ways of possible organizational changes for the health insurance system, making the most of the existing prerequisites. This can help to get closer to the goal of full coverage with health insurance services while achieving a positive social effect. The identified internal reserves make it possible to implement organizational changes without major reforms of the established health insurance system. No studies have been conducted in this perspective.
\end{abstract}

Keywords: health insurance system, aging, reform, Vietnam.

JEL Classification: G28, G32, G52.

Conference topic: Contemporary Organizations Development Management.

\section{Introduction}

Over the past few decades, the Government of Vietnam's policy of promoting market reforms and the "Comprehensive Renewal Policy" - Doi Moi ${ }^{1}$ - has led to major achievements in the socio-economic sphere of the country and created a comprehensive social (Le et al., 2020) and health insurance system (Chu et al., 2019). World Health Organization [WHO] (2019a) forecasts that in 30 years, the number of senior citizens (over 60) and senior citizens in extreme old age (over 75) who need support for everyday life in developing economies will increase fourfold. Therefore, WHO notes that the health systems of all countries must be restructured and adapted to the needs of older people.

As revealed in studies, the disease is one of the least predictable shocks for the household (Lee et al., 2019). This adverse event can completely undermine the household budget economically and it is one of the main sources of financial risk for the population (Scott et al., 2018; Grépin et al., 2020). Households with older members requir-

\footnotetext{
${ }^{1}$ Đổi Mới or "Renewal Policy" is a comprehensive program of reforms in the political, economic, social and cultural spheres of society, launched by the Communist Party of Vietnam (CPV) in 1986.
}

\footnotetext{
*E-mail: doanmaihmu@gmail.com
} 
ing permanent long-term care are under greater risk (Akiyama et al., 2018). Usually the main method of managing household financial risks is mandatory health insurance (Hasegawa, 2017). In Vietnam, such a system is still in the formation period, since its history counts only for 30 years (Doan, 2020).

Since 1989 (the new era of compulsory health insurance), Vietnam has made serious progress. In 2019, Vietnam's health spending amounted up to $\$ 17$ billion, equivalent to $5.7 \%$ of the country's GDP (KPMG, 2020), and by 2022, according to the World Bank, it will reach almost $11 \%$ (World Bank, 2019). The introduction of compulsory health insurance is also a fundamental factor in achieving the most important social goal "Universal well-being", set by the UN in the document "Agenda for Sustainable Development", which defines the UN Sustainable Development Goals until 2030 (Goal 3. Target 3.8 - Achieve universal health coverage, including protection financial risk protection access to quality essential health-care services and access to safe, effective, quality and affordable essential medicines and vaccines for all) (United Nations, 2015).

The purpose of this study is to identify the prerequisites for organizational changes of the emerging health insurance system in Vietnam.

Research on the health insurance system in Vietnam focuses, mainly on the study of its specifics (Nguyen et al., 2020), the problems of achieving universal health coverage and catastrophic household spending on health services, comparative analysis at the regional level (Wagstaff \& Neelsen, 2020; Grépin, 2016) but the studies of prerequisites (that is, the pre-existing conditions, which can become the basis for the reorganization of the existing health insurance system without major reforms have not been conducted.

It is important to notice that the current system of obligatory health insurance in Vietnam does not fulfill its main function - the financial protection for households in case of unfavorable events. Studies (Lee et al., 2019) of the use of mandatory health insurance mechanisms for household risk management show that there is a situation of adverse selection. The presence of a compulsory health insurance policy correlates only with an increase in the frequency of visits of insured persons to medical institutions which are located in the central cities of the country. At the same time, there is no correlation between the availability of compulsory health insurance and a decrease in additional household out-of-pocket expenses, and the same applies to catastrophic household spending on medical expenses. Moreover, the efficiency of the health insurance system is still quite low - according to the World Health Organization, more than $10 \%$ of households in the SRV spend more than $25 \%$ of their budget on medical expenses (WHO, 2019b). Such expenditures are recognized by the UN methodology as catastrophic and leave the household below the poverty line (Lee et al., 2019), which also hinders the achievement of the goal of universal health coverage set by the Government of the SRV (Kien et al., 2016). At the same time, new challenges (first of all, the aging of the country's population) can further aggravate the situation. Therefore, the search for such prerequisites (existing untapped opportunities) that can allow us to reformat the existing system, reduce the financial burden on the country's medical system and improve the quality of life of the country's population is an important task for modern Vietnam.

\section{Methodology}

Research methods used: comparative analysis, statistical analysis, case studies. Comparative analysis helps find answers to questions about how and why any system could react to perturbations of its parameters (Bukhari, 2011). Within the framework of statistical analysis, we conducted a sample statistical observation, a summary and grouping of statistical observation materials, and an analysis of absolute and relative statistical values. The case studies method provides the possibilities for exploration of a real issue within a defined context, using a variety of data sources (Baxter \& Jack, 2010; Bennett, 2001). The research proceeds more effectively through the combination of these methods (Johnson \& Onwuegbuzie, 2004).

For this research, the authors use data from open sources on the Internet, statistical information from the official websites of international organizations, rating agencies and regulators of financial markets in different countries. The authors analyzed more than 40 theoretical research papers and empirical studies on the topic under the study.

The study shows the ways of possible organizational changes of the health insurance system, making the most of the existing prerequisites. This can help to get closer to the goal of full coverage of the Vietnamese population with health insurance services while achieving a positive social effect. The identified internal reserves make it possible to make organizational changes without extra reform of the established health insurance system. No studies have been conducted in this perspective.

\section{Findings}

When analyzing scientific papers, Vietnam's social insurance legislation, statistics on the current socio-economic situation in Vietnam, and basic indicators of the development of health insurance, we have identified the following important features of the emerging health insurance system in the country: incomplete coverage of the health insurance system of the population; presence, along with the official, traditional medicine. 
Let's present them in more detail:

1) The continuing low level of income of the population, which prevents us from approaching the goal of universal coverage of the population by the median insurance system.

Thanks to the promotion of the mandatory health insurance system and the adoption of the landmark Law of Social Insurance in 2008, The Government launched a gradual expansion of the health system the coverage for the population. If the number of people insured under health insurance in 1989 was $5 \%$ of the population, then in 2019 this figure reached $87 \%$. The result was achieved by the regulatory reform of health care; state spending on health care were increased, as well as sources of funding for medical institutions were expanded.

In 2010 more than $20 \%$ of the population lived in poverty, in 2018 this figure fell down to $6.7 \%$ (see Figure 1). Despite the fact that the level of poverty in the country is gradually decreasing. Vietnam is still not able to achieve the goal of Universal health coverage (UHC) set by the Government of Vietnam (Nguyen et al., 2020). With the OECD's recommended no less than $10 \%$ of GDP spent on health, and with life expectancy lagging behind developed countries, the health and well-being of the population could become a bottleneck for Vietnam's transition to a higher income level.

Poverty facilitates the underdevelopment of the health insurance system. On the one hand, it is impossible for households with income below the subsistence level to buy a compulsory health insurance on their own, but on the other hand, the burden of spending on medical services without health insurance keeps the population in poverty. The resulting situation does not allow the poorest households to escape from the "poverty trap". The poorest citizens of Vietnam do not buy mandatory medical insurance, but prefer to use the services of traditional medicine, which is cheaper and they trust it. In addition, traditional Vietnamese medicine healers usually live close to such communities.

It should be noted that household spending on medical services has not decreased since 2012, and it is growing. Spending is higher than the average spending on health insurance for countries in the Easy Asia and Pacific region (excluding high income) (Figure 2). At the same time, the high level of spending by the poorest households can lead to financial disasters for households (Matsushima et al., 2020). According to the Vietnam Government Spending Survey, $2.5 \%$ of households, or about 2 million people, remain below the poverty line due to catastrophic health spending (Asia \& The Pacific Policy Society, 2019).

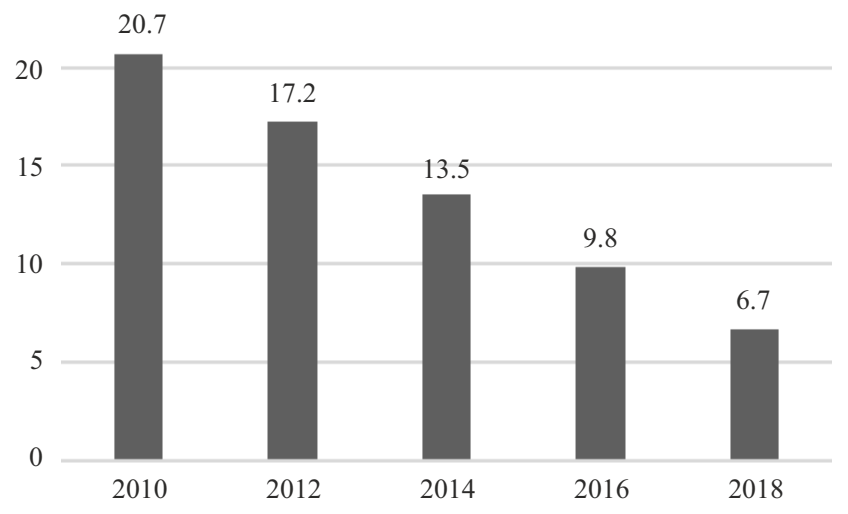

Figure 1. The share of population living below the subsistence minimum, Vietnam, \% of the total population, 2019 (compiled by the authors based on World Bank, 2021a)

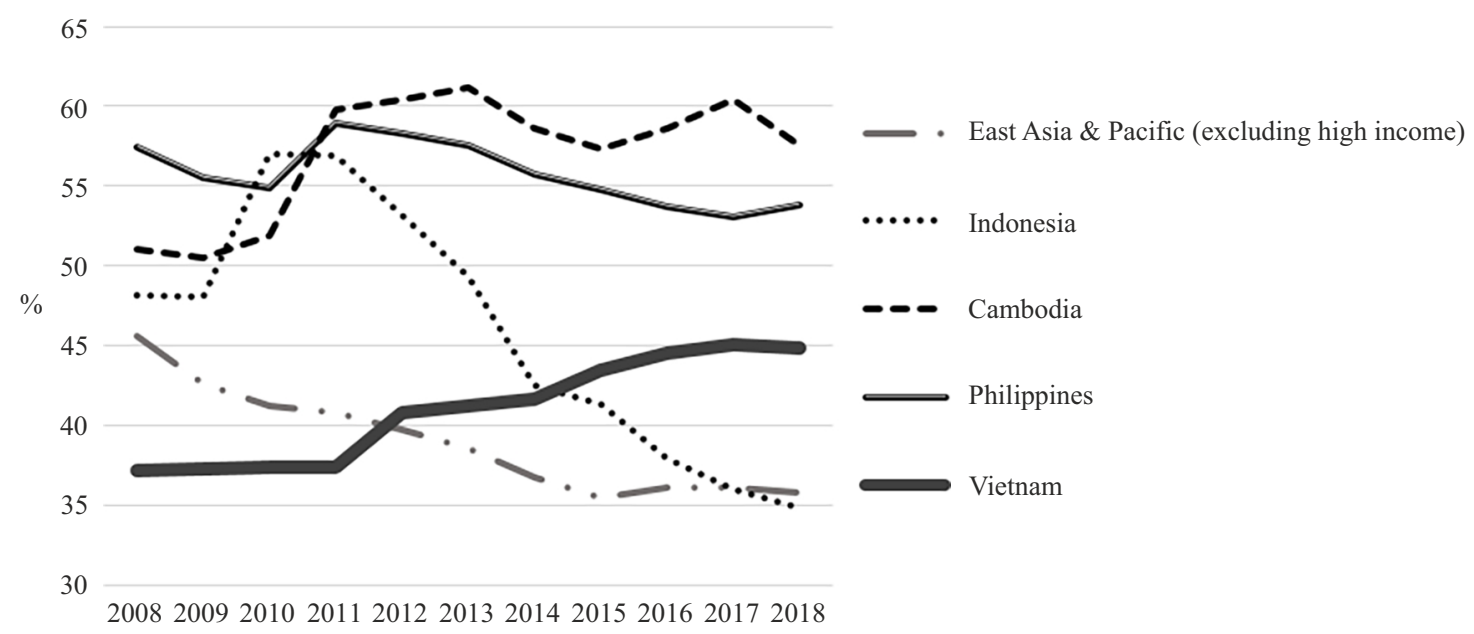

Figure 2. Out-of-pocket expenditure of Vietnam's households (\% of current health expenditure), 2008-2018 (compiled by the authors based on World Bank, 2021b) 
2) Existence, along with official, traditional medicine, which has the potential to expand the health insurance coverage for the poorest population.

Along with the official Western medicine, Traditional Eastern medicine (TM) also co-exists in Vietnam. The largest centers of traditional medicine in Hanoi and Ho Chi Minh City, as well as many small private clinics and individual healers throughout the country are being recognized officially at the state level (Nguyen et al., 2016). TM services are usually cheaper and therefore, more available for the poor Vietnamese people. TM healers usually offer their services at the level of local health centers in communes where the majority of the population is poor.

TM covers a variety of treatments, practices are vary by the region. Traditional medicine methods include herbs treatment, animal extracts and minerals usage (Adorisio et al., 2016). In addition, TM is rather popular non-drug therapies such as acupuncture, manual therapy, and spiritual practices (Pham et al., 2013).

Population aging as a challenge for the medical insurance system in Vietnam

Vietnam's health insurance sector has great threats due to the ongoing demographic and socio-economic changes in the country, primarily the aging population. The changes taking place in the society today create additional challenges: according to the United Nations Population Fund [UNFPA], Vietnam entered the "aging phase" back in 2011. It is expected that by 2038 about $20 \%$ of the country's population will be over 60 (UNFPA, 2019). Life expectancy in the country has increased significantly over the past 45 years: from 50.3 years in 1975 to 67.2 years in 1995 and reached 75 years by 2019 (KPMG, 2020).

This was superimposed on the urbanization of the population in Vietnam. In the period from 1960 to 2020 the number of urban residents more than doubled - in 1960, there were 27.97 million urban residents, and in $2020-60.61$ million people. A particularly massive influx into major cities and industrial zones such as Hanoi, Ho Chi Minh City and Da Nang was during 1994-1999 - about 1.2 million villagers migrated to urban areas to earn a living. Vietnam's rapid economic development has increased the demand for better and more specialized medical services, especially among the growing urban "new middle class".

As can be seen in Figure 3 the share of the urban population in the total population is growing. In 1960 only 15\% of the population in Vietnam lived in urban agglomerations, then in 2020 their number increased by almost 2.5 times and reached $38 \%$ of the total population. Urbanization also contributes to the process of change. An increase in the welfare and an increase in the life expectancy of the population changes the structure of labor relations, the structure of consumers themselves and their preferences in consumption (Kuznetsova et al., 2018). With an increase in urbanization, an increasing number of women make decisions about a later childbirth and fewer children in the family, which affects both a decrease in population growth and a change in the population structure in favor of older ages.

Table 1 shows the prospect of population growth in Vietnam, while maintaining the existing demographic trends in society, and is unfavorable. According to the forecasts presented in the World Data Atlas, until 2050 the minimum population growth will remain in Vietnam, but after 2055 the growth will turn into a negative zone.

Thus, a rapid decline in the birth rate along with an increase in life expectancy leads to an increase in the proportion of the elderly in the population structure (Galea et al., 2019). The fact that Vietnam is one of the fastest aging countries in Asia will have an important long-term implication for shaping the future demand for health care, household spending on health care, and therefore health insurance. It is expected that the share of the population aged 65+ by 2050 will increase two and a half times - from $7.1 \%$ in 2015 up to $18.0 \%$ by 2049 . According to the World Data Atlas, the retirement burden ratio (the number of people in age 65+ per 100 people aged 15-64) for the period from 2020 to 2050 will almost triple and in 2050 will amount to 32.8 according to forecasts, and by 2080 it will increase more than 4 times! (see Figure 4)

1960

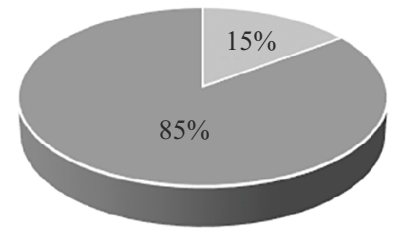

1990

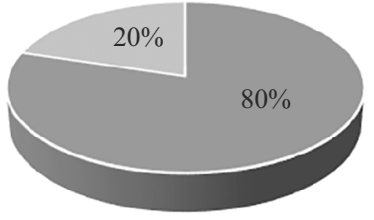

2020

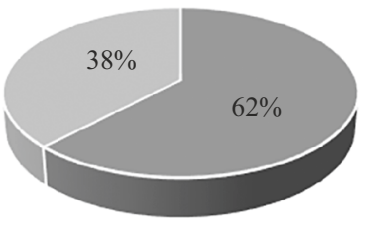

Urban

Rural area

Figure 3. Vietnam: the structure of the population in the context of urban/rural population (compiled by the authors according to the data of Worldometers, 2021)

Table 1. The perspective of the population growth rate in Vietnam, \%, 2020-2080 (compiled by the authors according to the data of World Data Atlas, 2021a)

\begin{tabular}{|c|c|c|c|c|c|c|c|c|c|c|c|c|}
\hline 2020 & 2025 & 2030 & 2035 & 2040 & 2045 & 2050 & 2055 & 2060 & 2065 & 2070 & 2075 & 2080 \\
\hline 0.9 & 0.7 & 0.5 & 0.3 & 0.2 & 0.2 & 0.1 & 0.00 & -0.1 & -0.2 & -0.3 & -0.3 & -0.3 \\
\hline
\end{tabular}




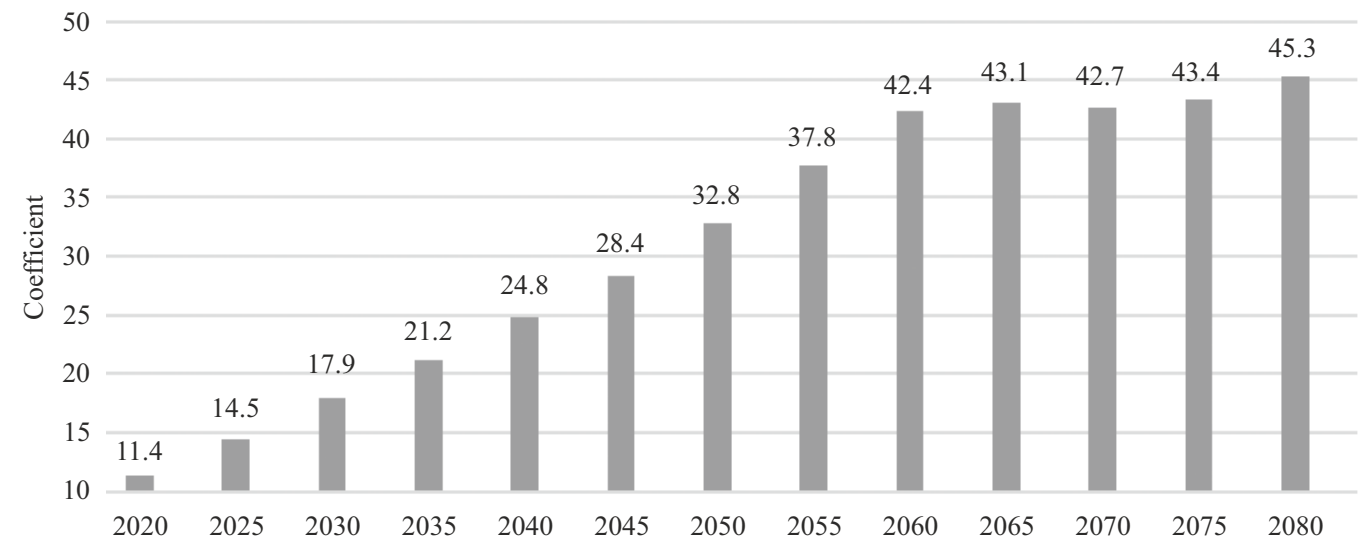

Figure 4. Forecast of the retirement burden coefficient, Vietnam, 2020-2080

(compiled by the authors according to the data of World Data Atlas, 2021b)

Table 2. Life expectancy in Vietnam, years

(compiled by the authors according to the data of World Data Atlas, 2021a, 2021b; Worldometers, 2021)

\begin{tabular}{|c|c|c|c|c|c|c|c|c|c|c|c|c|}
\hline 2020 & 2025 & 2030 & 2035 & 2040 & 2045 & 2050 & 2055 & 2060 & 2065 & 2070 & 2075 & 2080 \\
\hline 75.5 & 76.1 & 76.9 & 77.7 & 78.4 & 79.1 & 79.8 & 80.5 & 81.3 & 82.0 & 82.6 & 83.3 & 83.9 \\
\hline
\end{tabular}

This rate of population aging is high even compared to other East Asian countries (Ministry of Health of Vietnam and HPG, 2017) and slower only compared to China and Thailand. At the same time, life expectancy increases. The projection of life expectancy according to the World Data Atlas for Vietnam is presented in Table 2.

At the same time, with an increase in life expectancy, as noted in WHO studies, the survival time in Vietnam after 60 years is on average 22.7 years, but a person remains healthy only 17.2 years out of these years (World Bank, 2019). This implies a high need for personal health care program for older people in a deeper period of old age.

With an increase in the number of the elderly population, the population support coefficient - the number of people aged 20 to 64 for each person aged 65 and over - decreases. In 2015 the coefficient value was 9.3, then in 2050 its estimated value will drop to 2.6. In addition, the working-age population will be declining in absolute terms.

It is important to note that Vietnam's aging population is taking place at much lower household income levels than other Asian countries such as Japan, China, and the Republic of Korea (Abeywardhana, 2019). This raises questions about how the financial risks of "older" households will be managed and the increased demand for health care will be met. While Asia still has a norm that family members are responsible for caring of their elders, demographic changes such as declining fertility and the migration of the working-age population to cities make such expectations difficult to meet. Particular attention should be paid to remote rural areas, where medical care is practically unavailable. Under the circumstances, the availability of health insurance and hence medical care for the aging population of Vietnam, could be ensured by the widespread use of digital technologies in medicine and the organization of digital health insurance in Vietnam.

However, the health insurance system in Vietnam has internal resources that are not fully utilized. Using the potential of such opportunities could allow the Government to adopt organizational changes in health insurance system and improve its functioning, as well as avoid a new additional stage of reforms.

Let us consider the prerequisites, that is, the preliminary, already existing conditions for the possibility of implementing organizational changes in the health insurance system. Taking into account the following prerequisites will allow Government to facilitate reorganization of the health insurance system in such a way as to ensure its more efficiency without major reforms (Figure 5): 1) the cultural values of Asian society, which allow to build a community-based type model of living for the elderly on the basis of "equal with equal", to improve the quality of life, to simplify access to medical care; 2) technological advances in medicine that extend the healthy life of the elderly, 3) trust in traditional medicine, which allows widen the coverage of the poorest "elderly households".

The most important prerequisite for organizational transformation of the health insurance system is the cultural values of society based on mutual assistance - the possibility of organizing life activities on the basis of the principle of "equal with equal".

The countries of the East Asian region, also called Confucian Asia, share common cultural values and traditions, such as humanity, justice, trust, honesty, and courtesy. These cultural values and traditions are fundamental to Asian society (Karlova, 2007) and are deeply rooted in three religious and philosophical traditions: Confucianism, Buddhism, and Taoism. Vietnamese society also has a high degree of volunteerism and awareness of mutual support 


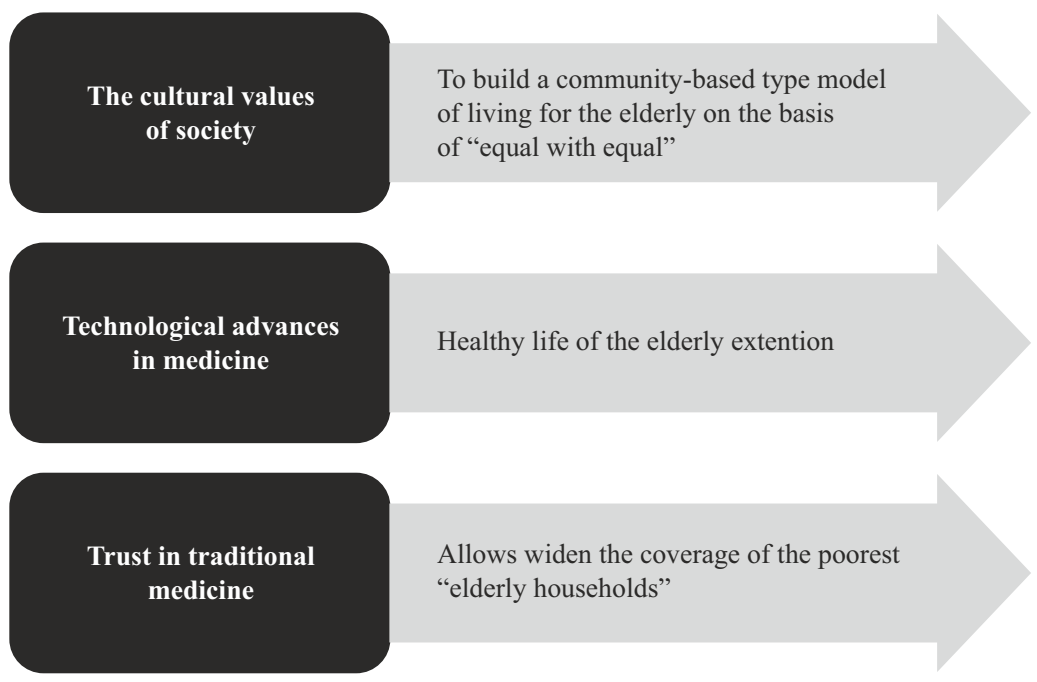

Figure 5. Preliminary, already existing conditions for the possibility of implementing organizational changes in the obligatory health insurance system (compiled by the authors based on Dalton et al., 2002; Hatano et al., 2017; Karlova, 2007)

(Dalton et al., 2002). Vietnam is a multinational and multilingual country. The values of Vietnamese society are based on its multi-faith nature, and traditional cultural values are based on tolerance, peacefulness, sacrifice, and love of one's neighbor (Tan, 2015; Nguyen, 2016).

In an agricultural-based, community-oriented society, in the past people donated to support the functioning of their communities and to help others less fortunate than themselves through various institutions-from village committees to temples/churches and clan associations. Such qualities inherent in the Vietnamese society can be useful in the formation of a community-based social insurance system in the country. The Japanese experience shows great prospects in this direction.

The population aging, the launch of pension reforms and reforms of the social and health insurance systems have forced the government of many countries, including Japan, to reconsider the concept of the functioning of the social insurance system (Pisarenko \& Belozyorov, 2015). The Japanese experience has become unique. After conducting an empirical experiment in the city of Mizugi, the Japanese Government created Community Centers for Comprehensive Care for the elderly in all district of the country. There were also changes in the state regulation of obligatory health insurance. The main task is provision of integrated care for the elderly. Community Centers include teams of nurses, social workers and care managers. The responsibilities of the Centers include: 1) prevention activities; 2) advocacy and counseling for older people in need of health care, using community-based health resource networks; 3) monitoring and training of "care managers" who are responsible for planning individual care services provided under longterm care insurance (Hatano et al., 2017). These centers are expected to play an important role in creating integrated health care systems in their communities and comfortable accommodation for the elderly with equal social status.

Why can the Japanese experience of organizing an integrated health insurance system for the elderly could be applied in Vietnam? In these circumstances, it is necessary to pay attention to a very important feature of Vietnam - extensive community ties. The communal type of compact residence of the elderly allows you to move from the burden on the family to the status of independence. Some Communes have been already developing their own unique programs and social security services for the care and support of the elderly, which can be transformed into insurance products for long-term health care. We can point out two emerging basic models of community-based care for the elderly in Vietnam: the ISHC model (Inter-generational Self-Help Clubs) for middle-income seniors and the religious model of the "Dieu Vien" Nursing Home for the less well-off elderly. In both cases, the basis is the competent management of the financial risks of the elderly on the basis of voluntary and compulsory health insurance similar to Japanese.

These two models have different goals, as evidenced by the significantly different living conditions of older people. The first mode: the majority of commune members are relatively healthy, active. The mission of the community is to improve the living conditions of the elderly, empower them, support their social status and «social inclusion», mutual assistance, preventive measures and medical care. Such expenses are easily tolerated by the elderly. In later periods of old age, there is a change in the propensity to save. According to research conducted by Horioka et al. (2019), during older periods there is a reverse process - a tendency to spend savings, associated primarily with the need for large health costs, increases in the amount of insurance premiums, and a decrease in social benefits. As the age increases, a person's views on the least important aspects of their well-being change. 
In the second model (Dieu Vien Nursing Home), the elderly are dependent due to an unfavorable economic situation, which means that they cannot stay with their family or live independently in the community. Therefore, the mission of the Dieu Vien Nursing Home is to meet the basic needs of such members (HelpAge International, 2014) by providing them with housing, clothing, food, medical care and emotional support.

In our opinion, it is the first ISHC model that can be considered as an option for the development of voluntary health insurance products for long-term care of the elderly. In this case, insurers can combine in a new insurance product the propensity of the population to a communal way of life and the increasing needs for medical care with age. The second model is closer to the principles of charity and is strongly influenced by the Buddhist values of Vietnamese society. As for the possibility of applying these models in different areas of Vietnam, the ISHC model, when implementing insurance principles, can be used both in rural areas, where financial resources are significantly limited, but cooperation can be confidently expected, and in more affluent urban agglomerations, which is very likely.

When organizing a community-based type of living for the elderly, an important element is the maximum extension of a healthy and relatively healthy period of life. This will be facilitated by compact living in the community, where medical care is provided on time (since there is a specialized medical center in the community), and during the recovery period, the person is not left alone, he feels support from the members of the commune. Social isolation is significantly reduced, the elderly communicate in an environment of equal social status and age, which has a positive effect on all body functions.

The second prerequisite for organizational changes in the health insurance system is technological advances in medicine that allow you to extend the healthy life of the elderly.

It is known that with increasing age, it becomes more and more necessary for a person to maintain health, as well as to extend a healthy period of life and appearance (Orešković, 2020). Aesthetic medicine and dentistry will also be highly demanded services for the aging population, provided that the welfare of households in the country increases. Note that aesthetic medicine is also quite an expensive service, but this does not reduce the motivation for investing in "prolonging youth" in this group of the population. In older age (and the proportion of such a population also increases with increasing life expectancy), the need for not only medical, but also specialized social services, as well as long-term care for the sick and lonely people increases.

At the same time, with an increase in life expectancy, as noted in WHO studies, the survival time in Vietnam after 60 years is on average 22.7 years, but at the same time a person remains healthy only 17.2 years of these years. This implies a higher need for personal medical care for the elderly in the deeper period of old age (Table 3).

Increasing healthy life expectancy is a key to reducing social insurance spending (Weber \& Loichinger, 2020).

The technological equivalent of the Japanese community organization of the health insurance system is the Chinese "mutual assistance platforms". They are designed to fill in the gaps in medical provision. Online health mutual aid programs have attracted more than 150 million participants in China in less than two years, but the lack of clear regulation of the emerging health insurance market, worth 5.4 billion yuan ( $\$ 760$ million), could expose participants to operational, financial and legal risks, industry experts say. The emerging market is dominated by Xiang $\mathrm{Hu}$ Bao, an online mutual assistance platform with more than 100 million members, which was introduced in October 2018 by Ant Financial Services Group's Alipay online payment platform. So far, this innovative insurance product is only available for customers under 59 years of age, but it is also expected to be adapted for older users.

Investments in medical R\&D, medical equipment, technologies, new innovative nanomaterials (Ivanov et al., 2020) allow to bring the provision of medical care to the elderly to a new level. This type of long-term investment by institutional investors, represented by pension funds, is made possible by the ever-increasing share of the world's elderly population. Pension funds, where participants in pension schemes are potential users of medical innovations (future pensioners), already occupy a significant share in the global market for biomedical research and development, although the main investor is still state-owned structures.

Table 3. Healthy life expectancy after 60 years, years (compiled by the authors based on World Bank, 2021d, 2021e; World Health Organization, 2021)

\begin{tabular}{|l|l|c|c|c|c|c|c|}
\hline \multirow{3}{*}{ Country } & \multicolumn{7}{|c|}{ Years } \\
\cline { 2 - 8 } & \multicolumn{1}{|c|}{ Type of data } & 2000 & 2005 & 2010 & 2015 & 2016 & 2019 \\
\hline \multirow{4}{*}{ Vietnam } & Male, years & 12.7 & 14.25 & 12.75 & 12.83 & 15.18 & 12.91 \\
\cline { 2 - 9 } & Female, years & 15.61 & 17.91 & 16.04 & 16.24 & 18.81 & 16.4 \\
\cline { 2 - 9 } & Both genders, years & 14.26 & 16.26 & 14.53 & 14.65 & 17.2 & 14.76 \\
\cline { 2 - 9 } & GDP, per cap, USD & 1987,303 & 2960,641 & 4213,296 & 6102,637 & 6573,096 & 8397,021 \\
\hline \multirow{5}{*}{ Japan } & Male, years & 16.7 & 17.33 & 17.84 & 18.39 & 18.7 & 18.82 \\
\cline { 2 - 9 } & Female, years & 20.5 & 21.99 & 21.34 & 21.54 & 22.93 & 21.85 \\
\cline { 2 - 9 } & Both genders, years & 18.74 & 19.81 & 19.69 & 20.04 & 20.91 & 20.39 \\
\cline { 2 - 9 } & GDP per cap, USD & 26838,69 & 31663,45 & 34987 & 30396,24 & 39970,68 & 43235,72 \\
\hline
\end{tabular}


Telecommunication innovations are becoming available to the elderly. Today, there are many smartphones designed specifically for the needs of the elderly. They have larger screens, larger, easy-to-read fonts, and simpler custom panels. Rehabilitation technologies, or assistive technologies (a common name for tools to facilitate the daily lives of people with disabilities) can improve the quality of life and reduce the dependence of older people with disabilities (Agree et al., 2005).

Over 20 years, the number of Internet users in Vietnam has grown from $0.25 \%$ in 1999 to $68.7 \%$ in 2019 (see Figure 6)

Moreover, the number of Internet users in the age group of 55-74 years in different countries (regardless of per capita income) is steadily increasing (Our World in Data, 2020). In Vietnam, the share of Internet users over the age of 55 is only $4 \%$, but it is gradually increasing. It is safe to say that the dynamics of this share is increasing, since the share of users in the previous age group already has access to the Internet $68.7 \%$ of the total population. It should be noted that the future generation of pensioners is now at the working age, for whom the use of the Internet and modern information and communication technologies have become a habitual way of life. Therefore, innovations that are somewhat more accessible and more accessible, such as simpler telemedicine, fitness/wellness, or monitoring platforms and solutions.

Remote access technologies can help solve another problem of Vietnamese healthcare - overcrowding in central hospitals (Vietnam Government, 2020). Yet in Vietnam the majority of citizens prefer to go to the Central city hospitals, bypassing the local clinic. This situation persists due to the shortage of highly qualified doctors in rural areas and in regional medical institutions. Transferring the initial consultation request to an electronic format will reduce the burden on central medical institutions.

An important advantage of telemedicine is an online conversation with a doctor. In recent years, there have been technological developments (for example, Beyond Verbal, Israel) that help to determine the patient's condition by voice. So-called vocal biomarkers allow you to assess the patient's condition and help identify serious diseases and health risks. This technology is vital for patients who may incorrectly assess or underestimate their condition, which will help determine the critical condition of the patient, psychiatric disorders, etc.

Unprecedented turbulence, including the insurance markets, in all over the world, caused by COVID-19 (Vylkova et al., 2020), has served as a catalyst for the transformation of the system of providing medical services, including in Vietnam. The diagnostic and treatment processes were adapted to allow for social distancing; therefore, the use of telemedicine was strongly encouraged. The Ministry of Health, in coordination with the Ministry of Information and Communications, has jointly created several simultaneous telemedicine projects launched on April 16, 2020. Preliminary results of a two-month pilot project have revealed the promising role of telemedicine in improving the quality of medical services in the digital age (The Ministry of Health of Vietnam, 2020). For more effective development, it was recently announced that the Project "Remote Medical Examination and Treatment" was approved by the Ministry of Health for the 5-year period 2020-2025 (Tran et al., 2021).

The program will be implemented on the basis of Hanoi Medical University Hospital together with several regional hospitals. The program will develop mobile applications and medical services to manage files and knowledge systems, as well as to help patients find medical information, make appointments and consult with doctors. These measures will accelerate the digitalization of Vietnam's entire hospital network, which is currently fragmented and mainly carried out in central-level public hospitals and private hospitals in major cities (Vietnam Times, 2020).

However, a number of digital technology obstacles remain in Vietnam, both public and private (Lam et al., 2018). First, healthcare professionals and patients are reluctant to use digital systems due to ignorance of these tools and technological limitations at home. Secondly, there are administrative barriers and bureaucratization for the introduction

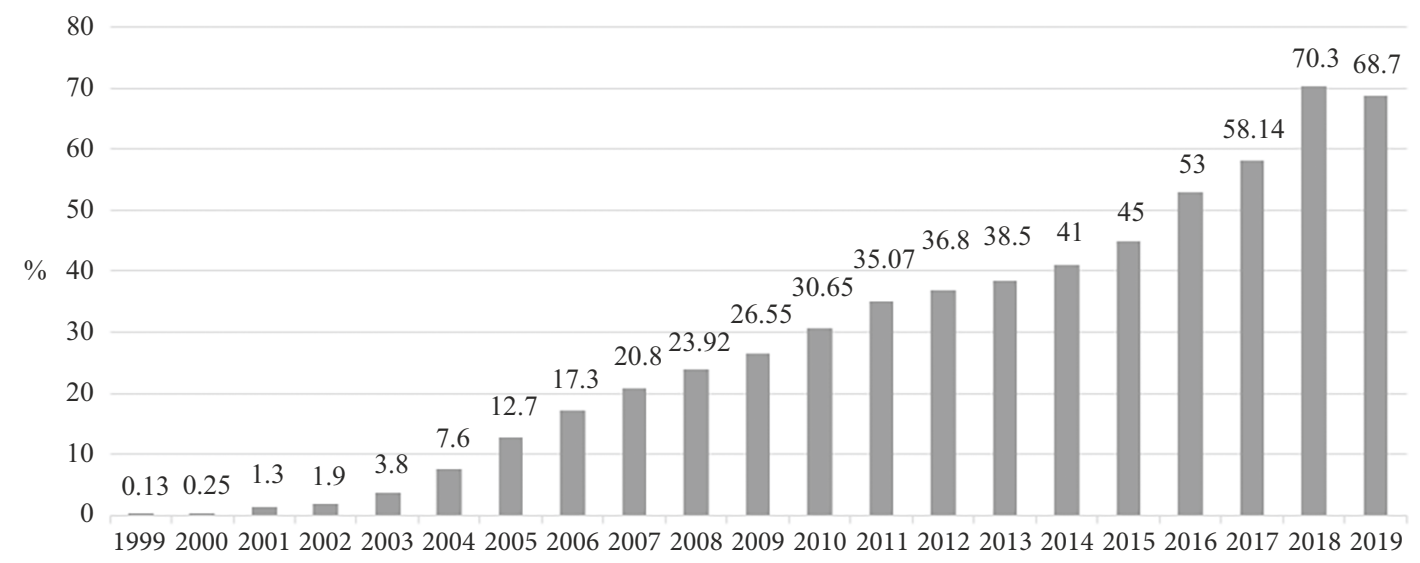

Figure 6. Using the Internet in Vietnam, \% of population, 1999-2019

(compiled by the authors according to the data of World Bank, 2021c) 
of information technologies (for example, to obtain an electronic signature, it is necessary to apply for approval to a number of instances). Thirdly, there is insufficient standardization, which reduces the effectiveness of inter-hospital communication.

The third prerequisite for improving the quality of health insurance system and its accessibility to vulnerable older members of the community is trust in traditional medicine.

The presence of this third prerequisite is conditioned by the peculiarity of the formed health insurance system in the SRV.

Expanding the coverage of traditional medicine (TM) into the health insurance should be a priority to Vietnam, as it will allow more of the poorest people living far from the central clinics to be included in the number of users of health insurance services (Nguyen et al., 2020). Also, the confidence of the poorest segments of the population in TM practices, satisfaction with such services, and willingness to pay for them (and, consequently, willingness to buy health insurance with TM services included) were identified among rural ethnic minority communities in Vietnam (Adorisio et al., 2016). The results of the research showed a high level of satisfaction with the services of TM, with more than $90 \%$ of respondents reporting an improvement in their health status when using traditional medicine methods. Indicators of the preference of TM over modern Western medicine are, first of all, the availability of medical services (the proximity of such medical institutions to rural communities), the traditions of some ethnic minorities, and gender (women trust traditional doctors more) (Wagstaff \& Neelsen, 2020). Thus, for additional impetus to the development of health insurance, it is necessary to take into account the rural communities and ethnic minorities of Vietnam and their preferences. Such a strategy will also achieve the goal of universal health coverage and improve the characteristics of the health insurance system in the country.

Vietnam has a long history of developing traditional medicine, so the Vietnamese government has set goals to broaden TM practices. By 2025, it is planned that $95 \%$ of local medical institutions will have TM units, and the rate of examination and treatment with TM methods should reach $25 \%$ and $30 \%$ of the total number of examinations and treatment in district medical institutions and in communes, respectively. However, statistics from the Vietnam Office of Traditional Medicine showed that the share of TM doctors is only $7.94 \%$ of the total number of Vietnamese doctors. The share of primary health care institutions providing health insurance coverage, where specialists with special qualifications in the field of traditional medicine work, has not yet reached $6 \%$ of the total number of health care workers.

\section{Conclusions}

We define the specific features of the current obligatory health insurance system in Vietnam. These features distinguish the health insurance system in Vietnam from developed countries. The specifics of the formation of the health insurance system in the SRV are as follows:

- The continuing low level of income of the population, which prevents us from approaching the goal of universal coverage of the population by the median insurance system;

- The availability of traditional medicine, along with official medicine, which has the potential to expand and include such services for the poorest people.

These features, under the influence of the most important challenge - the change in the structure of the population of Vietnam (population aging), allowed us to identify the prerequisites, that is, the reserves available in the system itself, which, if properly organized, can help improve the situation in the country's health insurance, without major reforms. The most important prerequisite for organizational transformation of the health insurance system is the cultural values of society based on mutual assistance - the possibility of organizing life activities on the basis of the principle of "equal with equal". The second prerequisite for organizational changes in the health insurance system is technological advances in medicine that allow you to extend the healthy life of the elderly. The third prerequisite for improving the quality of health insurance system and its accessibility to vulnerable older members of the community is trust in traditional medicine.

The identified possibilities require adequate actions of the Government to introduce organizational changes in the SRV health insurance system.

\section{References}

Abeywardhana, D. K. Y. (2019). The impact of ageing population on economic growth in South Asia. Asian Social Science, 15(7), 70. https://doi.org/10.5539/ass.v15n7p70

Adorisio, S., Fierabracci, A., Rossetto, A., Muscari, I., Nardicchi, V., Liberati, A. M., Riccardi, C., Van Sung, T., Trinh, Th. Th., \& Delfino, D. V. (2016). Integration of traditional and Western medicine in Vietnamese populations: a review of health perceptions and therapies. Natural Product Communications, 11(9), 1409-1416. https://doi.org/10.1177/1934578X1601100949

Agree, E. M., Freedman, V. A., Cornman, J. C., Wolf, D. A., \& Marcotte, J. E. (2005). Reconsidering substitution in long-term care: when does assistive technology take the place of personal care? The Journals of Gerontology. Series B, Psychological Sciences and Social Sciences, 60(5), S272-S280. https://doi.org/10.1093/geronb/60.5.S272 
Akiyama, N., Shiroiwa, T., Fukuda, T., Murashima, S., \& Hayashida, K. (2018). Healthcare costs for the elderly in Japan: Analysis of medical care and long-term care claim records. PloS One, 13(5), e0190392. https://doi.org/10.1371/journal.pone.0190392

Asia \& The Pacific Policy Society. (2019). Public healthcare in Vietnam drops 'the public'. https://www.policyforum.net/publichealthcare-in-vietnam-drops-the-public/

Baxter, P. E., \& Jack, S. M. (2010). Qualitative case study methodology: study design and implementation for novice researchers. The Qualitative Report, 13(4). https://doi.org/10.46743/2160-3715/2008.1573

Bennett, A. (2001). Case study: methods and analysis. In International encyclopedia of the social \& behavioral sciences (pp. 1513-1519). Pergamon. https://doi.org/10.1016/B0-08-043076-7/00751-8

Bukhari, S. A. H. (2011). What is comparative study. SSRN. https://doi.org/10.2139/ssrn.1962328

Chu, A., Kwon, S., \& Cowley, P. (2019). Health financing reforms for moving towards universal health coverage in the Western Pacific Region. Health Systems \& Reform, 5(1), 32-47. https://doi.org/10.1080/23288604.2018.1544029

Dalton, R. J., Pham, M. H., Pham, T. N., \& Ong, T. N. N. (2002). Social relations and social capital in Vietnam: findings from the 2001 world values survey. Comparative Sociology, 1(3/4), 369-386. https://doi.org/10.1163/156913302100418646

Doan, Th. M. (2020). Specifics of the development of the health insurance system in Vietnam. Problems of Modern Economy, 4(79), 144-149 http://www.m-economy.ru/art.php?nArtId=7019

Galea, S., Ettman, C. K., \& Vlahov, D. (2019). Urban health. Oxford University Press. https://doi.org/10.1093/oso/9780190915858.001.0001

Grépin, K. A. (2016). Private sector an important but not dominant provider of key health services in low- and middle-income countries. Health Affairs, 35(7), 1214-1221. https://doi.org/10.1377/hlthaff.2015.0862

Grépin, K. A., Irwin, B. R., \& Trakinsky, B. S. (2020). On the measurement of financial protection: an assessment of the usefulness of the catastrophic health expenditure indicator to monitor progress towards universal health coverage. Health Systems \& Reform, 6(1). https://doi.org/10.1080/23288604.2020.1744988

Hasegawa, M. (2017). Risk-coping measures against health shocks during the process of penetration of health insurance in Vietnam. Asian Economic Journal, 31(2), 139-164. https://doi.org/10.1111/asej.12118

Hatano, Y., Matsumoto, M., Okita, M., Inoue, K., Takeuchi, K., Tsutsui, T., Nishimura, S., \& Hayashi, T. (2017). The vanguard of community-based integrated care in Japan: The effect of a rural town on national policy. International Journal of Integrated Care, 17(2), 2. https://doi.org/10.5334/ijic.2451

HelpAge International. (2014). Why health systems must change: Addressing the needs of ageing populations in low-and middle-income countries. http:/www.helpage.org/global-agewatch/reports/helpage-briefing-why-health-systems-must-change/

Horioka, Y., Gahramanov, E., Hayat, A., \& Tang, X. (2019). The impact of bequest motives on retirement behavior in Japan: A theoretical and empirical analysis. AGI Working Paper Series 2019-14, Asian Growth Research Institute. https://doi.org/10.3386/w26621

Ivanov, L. A., Demenev, A.V., Pisarenko, Zh. V., \& Wang, Q. (2020). Nanotechnologies: a review of inventions and utility models. Part III. Nanotechnologies in Construction, 12(3), 140-146. https://doi.org/10.15828/2075-8545-2020-12-3-140-146

Johnson, R. B., \& Onwuegbuzie, A. J. (2004). Mixed methods research: a research paradigm whose time has come. Educational Researcher, 33(7), 14-26. https://doi.org/10.3102/0013189X033007014

Karlova, P. (2007). A response to the West: a comparative study between Vietnam and Japan (2007). Archivorientální: Quarterly Journal of African and Asian Studies, 75(1), 61-74. https://www.academia.edu/18551646/A_Response_to_the_West_A_Comparative_Study_between_Vietnam_and_Japan

Kien, V. D., Van Minh, H., Giang, K. B., Dao, A., Tuan, L. Th., \& Ng, N. (2016). Socioeconomic inequalities in catastrophic health expenditure and impoverishment associated with non-communicable diseases in urban Hanoi, Vietnam. International Journal for Equity in Health, 15, article number 169. https://doi.org/10.1186/s12939-016-0460-3

KPMG. (2020). The power of self-care in achieving health for all. https://assets.kpmg/content/dam/kpmg/vn/pdf/publication/2020/8/ The-Power-of-Self-Care-in-Achieving-Health-for-All.pdf

Kuznetsova, N., Pisarenko, Zh., \& Lobanova, L. (2018). Financial conglomerate identification by financial markets regulators: case of developed and emerging market economies. In 2018 10th International Scientific Conference "Business and Management 2018”, Conference Proceedings (pp. 444-455). Vilnius Gediminas Technical University. https://doi.org/10.3846/bm.2018.49

Lam, J. A., Dang, L. T., Phan, N. T., Trinh, H. T., Vu, N. C., \& Nguyen, C. K. (2018). Mobile health initiatives in Vietnam: scoping study. JMIR Mhealth Uhealth, 6(4), e106. https://doi.org/10.2196/mhealth.8639

Lee, H.-Y., Oh, J., Hoang, Van M., Moon, J. R., \& Subramanian, S. V. (2019). Use of high-level health facilities and catastrophic expenditure in Vietnam: can health insurance moderate this relationship? BMC Health Services Research, 19(1), 318. https://doi.org/10.1186/s12913-019-4115-0

Le, Q. L., Blizzard, L., Si, L., Giang, L. Th., \& Neil, A. L. (2020). The evolution of social health insurance in Vietnam and its role towards achieving universal health coverage. Health Policy OPEN, 1, 100011. https://doi.org/10.1016/j.hpopen.2020.100011

Matsushima, M., Yamada, H., \& Shimamura, Y. (2020). Analysis on demand- and supply-side responses during the expansion of health insurance coverage in Vietnam: Challenges and policy implications toward universal health coverage. Review of Development Economics, 24(1), 144-166. https://doi.org/10.1111/rode.12627

Ministry of Health of Vietnam and HP. (2017). Thematic HPG Group Meeting 2017: Opening remark of JICA co-chair. https://moh. gov.vn/web/ministry-of-health/top-news/-/asset_publisher/EPLuO8YEhk19/content/thematic-hpg-group-meeting-2017-opening-remark-of-jica-co-chair?inheritRedirect=false

Nguyen, L. T., Kaptchuk, T. J., Davis, R. B., Nguyen, G., Pham, V., Tringale, S. M., Loh, Y. L., \& Gardiner, P. (2016). The use of traditional Vietnamese medicine among Vietnamese immigrants attending an urban community health center in the United States. Journal of Alternative and Complementary Medicine, 22(2), 145-153. https://doi.org/10.1089/acm.2014.0209 
Nguyen, Q. T. N. (2016). The Vietnamese values system: a blend of oriental, Western and socialist values. International Education Studies, 9(12), 32-40. https://doi.org/10.5539/ies.v9n12p32

Nguyen, T. T., Nguyen, Q. N., Truong, D. V., Ngo, T. T., Vu, H. N., \& Mac, T. D. (2020). Awareness practices, and demands of traditional medicine providers for continuous medical education in district hospitals of Vietnam. Evidence Based Complement Alternative Medicine, 2020, article ID 9852969. https://doi.org/10.1155/2020/9852969

Orešković, S. (2020). No country for old men: five prevalent stereotypes affecting the life of the elderly. Croatian Medical Journal, 61(2), 184-188. https://doi.org/10.3325/cmj.2020.61.184

Our World in Data. (2020). The Internet's history has just begun. https://ourworldindata.org/internet

Pham, D. D., Yoo, J. H., Tran, B. Q., \& Ta, T. T. (2013). Complementary and alternative medicine use among physicians in oriental medicine hospitals in Vietnam: a hospital-based survey. Evidence-Based Complementary and Alternative Medicine, 2013, Article ID 392191. https://doi.org/10.1155/2013/392191

Pisarenko, Zh. V., \& Belozyorov, S. A. (2015). Pension reforms in countries with developed and transitional economies. Economy of Region, (4), 158-169. https://doi.org/10.17059/2015-4-13

The Ministry of Health of Vietnam. (2020). Ministry of Health plan on telemedicine. https://moh.gov.vn/tin-noi-bat/-/asset_publisher/3Yst7YhbkA5j/content/hoi-thao-trien-khai-e-an-kham-chua-benh-tu-xa-giai-oan-2020-2025

Tan, P. (2015). Study on current public opinion in Vietnam based on universally value system and core values approach. Open Journal of Social Sciences, 3, 113-119. https://doi.org/10.4236/jss.2015.32015

Tran, T., Tang, Sh., \& Mao, W. (2021). Getting to universal health coverage in China and Vietnam. https://www.brookings.edu/ blog/future-development/2021/02/03/getting-to-universal-health-coverage-in-china-and-vietnam/

United Nations Population Fund (UNFPA). https://www.unfpa.org/

United Nations. (2015). Resolution adopted by the General Assembly on 25 September 2015, Transforming our world: the 2030 Agenda for Sustainable Development (A/RES/70/1)

Vietnam Government. (2020). Result of the Viet nam household standards survey 2018. https://www.gso.gov.vn/wp-content/uploads/2020/05/VHLSS2018.pdf

Vietnam Times. (2020). Prospects for Vietnam's healthcare industry optimize investors. https://vietnamtimes.org.vn/prospects-for-vietnams-healthcare-industry-optimize-investors-22684.html

Vylkova, E. S., Grishin, S. E., Labudin, A., Naumov, V., Petrova, I., Pisarenko, Zh. V., \& Fedotov, D. (2020). Russia and the world during and after the COVID-19 pandemic: challenges and opportunities [Collective monograph] (274 p.). Publishing and Printing Association of Higher Educational Institutions.

Wagstaff, A., \& Neelsen, S. (2020). A comprehensive assessment of universal health coverage in 111 countries: a retrospective observational study. Global Health, 8(1), E39-E49. https://doi.org/10.1016/S2214-109X(19)30463-2

Weber, D., \& Loichinger, E. (2020). Live longer, retire later? Developments of healthy life expectancies and working life expectancies between age 50-59 and age 60-69 in Europe. European Journal of Ageing, 2020. https://doi.org/10.1007/s10433-020-00592-5

World Bank. (2019). The future of health financing in Vietnam: ensuring sufficiency, efficiency and-sustainability. http://documents1.worldbank.org/curated/en/222831563548465796/pdf/The-Future-of-Health-Financing-in-Vietnam-Ensuring-Sufficiency-Efficiency-and-Sustainability.pdf

World Bank. (2021a). Multidimensional poverty headcount ratio, household (\% of total households) - Vietnam. https://data.worldbank.org/indicator/SI.POV.MDIM.HH?end=2018\&locations=VN\&start=2018\&viw=bar

World Bank. (2021b). Out-of-pocket expenditure (\% of current health expenditure). https://data.worldbank.org/indicator/SH.XPD. OOPC.CH.ZS

World Bank. (2021c). Individuals using the Internet (\% of population) - Vietnam. https://data.worldbank.org/indicator/IT.NET. USER.ZS? end $=2019 \&$ locations $=$ VN\&start $=1999$

World Bank. (2021d). GPD per capita, PPP (current international \$) - Vietnam. https://data.worldbank.org/indicator/NY.GDP. PCAP.PP.CD?locations $=\mathrm{VN}$

World Bank. (2021e). GPD per capita, PPP (current international \$). https://data.worldbank.org/indicator/NY.GDP.PCAP. PP.CD?locations $=\mathrm{JPF}$

World Data Atlas. (2021a). World and regional statistics, national data, maps, rankings. https://www.knoema.ru/atlas/Вьетнам/ topics/

World Data Atlas (2021b). World and regional statistics, national data, maps, rankings. https://www. knoema.ru/atlas/

World Health Organization. (2019a). Universal health coverage in Viet Nam. https://www.who.int/vietnam/health-topics/universal-health-coverage

World Health Organization. (2019b). 10-facts-on-ageing-and-health. https://www.who.int/news-room/fact-sheets/detail/10-factson-ageing-and-health

World Health Organization. (2021). Maternal, newborn, child and adolescent health and ageing. Data portal. https://www.who. $\mathrm{int} / \mathrm{data} / \mathrm{maternal-newborn-child-adolescent-ageing/indicator-explorer-new/mca/healthy-life-expectancy-at-age-60/}$

Worldometers. (2021). Vietnam demographics. https://www.worldometers.info/demographics/vietnam-demographics/ 